\title{
The concept of virginity from the perspective of Iranian adolescents: a qualitative study
}

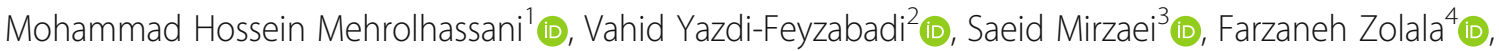 \\ Ali-Akbar Haghdoost ${ }^{5}$ (D) and Nadia Oroomiei ${ }^{3,6^{*}}$ (i)
}

\begin{abstract}
Background: Premarital sex can increase the risk of sexually transmitted diseases (STDs) in adolescents, and lack of premarital sex can be considered as a reliable policy for STD prevention, which is used by some countries such as Iran. Since the success of this policy is related to the concept of virginity, the present study was conducted to determine the concept of virginity from the perspective of Iranian adolescents.

Methods: In this qualitative study with phenomenological approach, the research team visited public places, including parks and coffee shops, and interviewed a number of 15-19-year-old adolescents. The data were collected using in-depth interviews with semi-structured questions and analysed using thematic analysis method.

Results: Several themes, including virginity as the lack of emotional relationship with the opposite sex, lack of physical contact, nonpenetrative relationship, virginity as a myth, virginity as a commitment, having an intact hymen, and not knowing the meaning of virginity, were extracted from the data.

Conclusion: The most reliable policy on STD prevention is the lack of premarital sex. The success of this policy is related to the concept of virginity. The findings of this study showed that the participants did not consider physical contact as the breach of virginity. This may indicate that the policy of not having sex before marriage or lack of premarital sex is not enough and Iranian adolescents are at risk of STDs. Therefore, policymakers must take steps towards modifying the concept of virginity in the adolescents' value system and provide and implement educational programs on sexual health for adolescents.
\end{abstract}

Keywords: Virginity, Adolescents, Iran, Virginity policy

\section{Background}

Sexually transmitted infections (STIs) such as HIV, chlamydia, and syphilis are among the main health problems in the world and have a high prevalence in the Middle East and North Africa (MENA) region [1]. The MENA region is the third fastest-growing HIV/AIDS epidemic

\footnotetext{
* Correspondence: n_oroomiei@yahoo.com

${ }^{3}$ Health Policy, Department of Health Management, Policy and Economics, School of Public Health, Bam University of Medical Sciences, Bam, Iran

${ }^{6}$ Bam University of Medical Sciences, Sardaran Shahid Square - Shahid Rajaei Boulevard, Bam Postal Code: 7616913555, Iran

Full list of author information is available at the end of the article
}

in the world. Statistics show that HIV and STIs are more prevalent in 15-29 age group [2]. Accordingly, there are concerns about the widespread epidemics in the MENA countries and the risk of HIV/AIDS and STDs among adolescents [3]. Sexual health education is an effective prevention strategy that reduces the risk of STDs [4]. However, as premarital sexual behaviour is not accepted in many countries in this region and sexual health education is limited by economic, cultural, political, and religious factors [3], and there is limited access to sexual health education, little education is offered to single

(c) The Author(s). 2020 Open Access This article is licensed under a Creative Commons Attribution 4.0 International License, which permits use, sharing, adaptation, distribution and reproduction in any medium or format, as long as you give appropriate credit to the original author(s) and the source, provide a link to the Creative Commons licence, and indicate if changes were made. The images or other third party material in this article are included in the article's Creative Commons licence, unless indicated otherwise in a credit line to the material. If material is not included in the article's Creative Commons licence and your intended use is not permitted by statutory regulation or exceeds the permitted use, you will need to obtain permission directly from the copyright holder. To view a copy of this licence, visit http://creativecommons.org/licenses/by/4.0/. The Creative Commons Public Domain Dedication waiver (http://creativecommons.org/publicdomain/zero/1.0/) applies to the data made available in this article, unless otherwise stated in a credit line to the data. 
people about high-risk sexual behaviours. Hence, virginity as a tradition or a religious value can become a tool to prevent STIs $[4,5]$.

Virginity as the lack of sexual intercourse before marriage has been considered as a value and sign of piety in many religions for centuries [6]. Nevertheless, the cultural and social place of virginity and the attitude of people toward premarital sexual relationship has been changed considerably within the last few years following the incorrect perceptions of virginity and changes in the world value system [7]. Premarital sex is accepted in many countries and measures have been taken to secure this relationship [8]. On the other hand, in some countries, virginity is considered a value for females, especially at the time of marriage. It is considered as a sign of woman's chastity and respectability [9]. For example, in Zimbabwe, a woman's virginity is a sign of loyalty to marital life. Generally, different countries have different approaches to this subject, which is based on their cultural and religious context [10].

Iran is a MENA country with Islamic ideology where sexual relationships are accepted only within the marriage framework. Also, fathers' permission is needed for females in their first marriage. In Iran, only a one-day mandatory training session, known as compulsory training, is held for newly engaged couples as premarriage education, and no other formal education on sexual behaviour is provided for young people [11]. In the context of Iran, sexual relation outside marriage is prohibited by law and religion, and it is associated with penalties and punishments [12]. For example, if a female with no previous marriage history gets married and hides her lack of virginity from her husband, the law allows the husband to divorce her [13, 14]. Therefore, girls' virginity in the context of Iran is of great importance and lack of virginity is considered a stigma. Accordingly, any emotional relationship and contact between men and women outside marriage are unacceptable and the stigma of such relationship is much greater for women than for men [15]. Most of the women who break the taboo of premarital sex undergo hymenoplasty to increase their chances of successful marriage [16]. Adolescents are at a serious risk of premarital sex [17].

In Iran, adolescents' (14\%) behaviours affect their health and the health of next generations $[18,19]$. Moreover, due to biological changes that occur naturally during adolescence period, the desire to establish a relationship with the opposite sex is intense [20]. Therefore, this kind of relationship may have many consequences, such as losing virginity, unwanted pregnancy, illegal abortion, transmission of AIDS and other STDs, illegal hymenoplasty, depression, leaving school, conflict between parents and their divorce, social exclusion, violence, and even honour killings [16].
Virginity as an abstinence strategy is the main strategy of Iranian policymakers to counter high-risk sexual behaviours of unmarried people. In fact, from the policymakers' point of view, virginity means having no sex. As lack of virginity before marriage is not acceptable in the Iranian society, the policymakers assume that the prevalence of premarriage sexual relations is insignificant, and thus there is no considerable risk of STDs for single people [21].

Although keeping virginity claims to be the most reliable policy for STDs, the success of this policy is closely related to the meaning and definition of virginity [22, 23]. In Iran, this policy has been adopted because of the unacceptability of premarital sex in Iran, which is also reinforced by national laws. However, the following question is raised: Does virginity mean not having sex from Iranian adolescents' perspective? Or does it have a different meaning from the Iranian adolescents' perspective? In this case, the policymakers need to adopt other policies in addition to the abstinence policy to prevent STDs in adolescents. Thus, the aim of this study was to determine the concept of virginity and purity from the perspective of Iranian adolescents.

\section{Setting}

This study was conducted in Kerman, the capital of Iran's largest province, located in southeastern Iran. According to the Census of 2017, the population of Kerman was 632,162 and the population of 10-19-year-olds was 93,552 [24].

\section{Methods}

Study design

This was an exploratory qualitative study and the research team aimed to explore adolescents' perceptions of virginity. Also, a phenomenological framework was used in this study. The study population included all adolescents living in Kerman. Participants were identified using convenience sampling method. Inclusion criteria were as follow: (1) being an adolescent and (2) willingness to participate in the study. Although schools were suitable sites for sampling, Iran's Ministry of Education does not allow the conduction of studies on sex-related issues in schools. Therefore, due to the lack of cooperation of the Ministry of Education, the researcher attended sites where adolescents were more likely to be present. To select samples, the research team visited different public places such as parks, coffee shops, shopping malls, hookah houses, computer game centres, sports clubs, and mosques in different neighbourhoods (poor, middle class, and rich). The research was fully described to the participants in public places, and the researcher provided the adolescents with a contact number and asked them 
to contact the researcher if they decided to participate in the study.

Then, after explaining the study objectives and obtaining written informed consent, those who were willing to participate in the study were selected. Appointments were set with the participants and they were asked to attend to the meeting room in the Management and Medical Informatics Faculty in Kerman University of Medical Sciences, where interviews were conducted individually.

Based on the ethics fundamental regulations in medical science research in Iran, informed consent should be obtained only from the participants if they are 15 years old or over. Thus, in this study, informed consent was obtained only from the participants. A total of $18 \mathrm{fe}-$ males and 18 males were enrolled in the study. The females aged between 15 and 19 and the males between 16 and 19 years. Also, 26 participants were high school students, and 10 participants were university freshmen. All participants lived in Kerman and with their parents. None of the participants had jobs. Also, 6 participants stated that they were religious.

\section{Data collection}

The information gathering method was the in-depth interview using semi-structured questions. The interviews were conducted by a member of the research team (N.O). On the 33rd interview, the data were saturated, but three more interviews were conducted for more certainty. After granting the permission of participants, the interviews were recorded by a voice recorder. The interviews were conducted in Persian and each lasted 15 to $50 \mathrm{~min}$.

\section{Data analysis}

One of the authors listened to the audio files of the interviews repeatedly (NO). Verbatim transcription was performed by one of the authors (NO). Two authors (e.g., NO and VYF) read implemented interviews for many times, and encoded the implemented interviews and searched the data for frequently repeated themes [25]. Then, two authors look over the codes, identified the patterns, and developed the themes. MAXQDA-V10 software was used to encode the data. The data were analysed inductively. Two other authors (MHM and $\mathrm{SM}$ ) examined the emerging themes and ambiguities to ensure the consistency and validity of the interpretations. Next, the extracted themes were reviewed by another author, disagreements were discussed during a meeting with all members of the research team, and the themes were finalized. Finally, sustained themes were identified using constant comparisons and analytic induction. To ensure transferability, an attempt was made to use a sample of adolescents with the highest variation. Also authors attempted to present in-depth descriptions of the study method and findings. For the credibility and confirmability assurance, the copied text and its analysis were submitted to the research team and their corrective recommendations and comments were applied. Also researcher triangulation technique was used, and researchers had prolonged engagement with data.

\section{Ethical considerations}

This study was approved by the Ethics Committee of Kerman University of Medical Sciences. The participants were assured about the confidentiality of their information and the objectives of interviewers, which were for the academic purposes. They were also informed that taking part in the study is voluntary and they could leave the interview at any time without any reason. A written informed consent was obtained from the participants and the purpose of study was fully explained to them. The interviewees were also assured that the sound recording will be stopped at any time. The interviews were initially implemented, and each interview was given an identification code to ensure confidentiality. Also, to ensure data confidentiality, all computers were secured with passwords.

\section{Results}

The participants aged between 15 and 19 years. According to the findings of the present study, virginity had different concepts for the participants. The concept of virginity stated by the teenagers were classified into three main themes (Table 1): (1) nonacceptance of physical intimacy, with two subthemes of lack of any emotional relationship with the opposite sex and lack of physical contact; (2) acceptance of physical intimacy, with four subthemes of none penetrative relationship, virginity as a myth, virginity as a commitment, having an intact hymen, and (3) not knowing the meaning of virginity. All the interviewees, except for two females, believed that virginity is something that concerns women and not men.

\section{Nonacceptance of physical intimacy}

The first main theme was nonacceptance of physical intimacy. The theme means that from the perspective of some participants $(N=7)$, virginity means no physical intimacy, including close friendship, romantic love, or sexual attraction. This theme has two subthemes: lack of any emotional relationship with the opposite sex and lack of physical contact.

Lack of any emotional relationship with the opposite sex The first identified subtheme in this study was the lack of any emotional relationship with the opposite sex. This code was mentioned only by two female interviewees. The interviewees perceived virginity as lack of any 
Table 1 Findings of the Study

\begin{tabular}{|c|c|c|c|}
\hline Main themes & Subthemes & Number of Participants & \\
\hline \multirow[t]{2}{*}{$\begin{array}{l}\text { Nonacceptance of } \\
\text { physical intimacy }\end{array}$} & $\begin{array}{l}\text { Lack of any emotional } \\
\text { relationship with the } \\
\text { opposite sex }\end{array}$ & Two female interviewees & $\begin{array}{l}\text { "Being a virgin means having no emotional connection with any man, } \\
\text { except one's husband." } \\
\text { "According to Islamic teachings, an emotional connection with any man } \\
\text { other than one's husband is not acceptable." }\end{array}$ \\
\hline & Lack of physical contact & $\begin{array}{l}\text { Five interviewees (four } \\
\text { females and one male) }\end{array}$ & $\begin{array}{l}\text { "I think it's okay to love a woman even if you text or call her but you } \\
\text { shouldn't have physical contact." } \\
\text { "An emotional relationship is ok as long as the man and woman don't } \\
\text { touch each other and only call or talk to one another." }\end{array}$ \\
\hline \multirow[t]{4}{*}{$\begin{array}{l}\text { Acceptance of } \\
\text { physical intimacy }\end{array}$} & $\begin{array}{l}\text { Nonpenetrative } \\
\text { relationship }\end{array}$ & $\begin{array}{l}\text { Four participants (two } \\
\text { females and two males) }\end{array}$ & $\begin{array}{l}\text { "....It means not having sex....." } \\
\text { "I am still virgin when I flirt but I should not have sex." } \\
\text { "Do you think kissing makes you not a virgin anymore? Not until you } \\
\text { have sex." }\end{array}$ \\
\hline & Virginity as a myth & $\begin{array}{l}\text { Three of the female } \\
\text { interviewees }\end{array}$ & $\begin{array}{l}\text { "The concept of virginity is ridiculous. What wise person would believe } \\
\text { this?" } \\
\text { "It's a lie. It wants to say to women that they are not equal to men. It } \\
\text { deprives free sexual relationship, while it is an absolute right." }\end{array}$ \\
\hline & Virginity as a commitment & $\begin{array}{l}\text { Five interviewees (three } \\
\text { males and two females) }\end{array}$ & $\begin{array}{l}\text { "... Virginity means loyalty to your boyfriend.' } \\
\text { "It means only being with your girlfriend." } \\
\text { "Virginity means being faithful to your sexual partner. It could be your } \\
\text { boyfriend or husband. There is no difference between a boyfriend or a } \\
\text { husband." }\end{array}$ \\
\hline & Having an intact hymen & $\begin{array}{l}\text { Fourteen of the } \\
\text { interviewees (nine females } \\
\text { and five males) }\end{array}$ & $\begin{array}{l}\text { ".... Not having vaginal sex" } \\
\text { "For example, I can have anal sex so that my virginity is maintained." } \\
\text { "....it means having a hymen...." } \\
\text { "It does not mean having no sex. It means having a hymen, which } \\
\text { means you can have other types of sex." }\end{array}$ \\
\hline $\begin{array}{l}\text { Not knowing the } \\
\text { meaning of } \\
\text { virginity }\end{array}$ & & $\begin{array}{l}\text { Three of the interviewees } \\
\text { (Three females) }\end{array}$ & \\
\hline
\end{tabular}

emotional relationship with the opposite sex. They believed that having an emotional relationship with the opposite sex outside marriage is contrary to Islamic teachings and a good Muslim should respect the Islamic laws. Moreover, they believed that the concept of virginity is not only for women, and from the perspective of Islam, having an emotional attachment to the opposite sex outside marriage is taboo for both men and women. For example, the interviewee number 2 (a female) stated, "We are either a Muslim or not. If we are, we should do whatever our religion tells us to do. If our religion says a man and a woman should have no emotional relationship outside marriage, we must accept it. As a Muslim, if $I$ have a relationship with the opposite sex even via phone, I am not a virgin."

\section{Lack of physical contact}

The second identified subtheme in this study was the lack of physical contact. Moreover, five interviewees (four females and one male) believed that virginity means lack of physical contact between a woman and a man before marriage, which includes pats on the back, touches on the arm, shoulder, or face, hugs, and holding hands. Having an emotional relationship with the opposite sex via phone, chat, and even going on dates is acceptable and even necessary if there is no physical contact. They considered these relationships necessary for getting to know their potential spouses. However, having physical contact was not acceptable to them and they considered a sin. The interviewee number 5 (a female) said, "Without communicating with the opposite sex, it is impossible to make a decision for marriage, but you have to control yourself. I mean, if I have a date with a man, I'm still a virgin, but I should not have physical contact with him because it is a sin based on Islamic teachings." This narrative points out that adolescents have different understandings of Islamic teachings about relationships with the opposite sex and committing a sin.

\section{Acceptance of physical intimacy}

The second main theme was acceptance of physical intimacy. The theme means that from the perspective of some participants $(N=26)$, virginity means a range of physical intimacy that includes sexual activity. However, this range was different among the participants. This theme contains four subthemes: nonpenetrative relationship, virginity as a myth, virginity as a commitment, and having an intact hymen.

\section{Nonepenetrative relationship}

The first identified subtheme was nonpenetrative relationship. Four participants (two females and two males) 
believed that emotional relationship between a man and a woman is inevitable, and physical intimacy such as hugging and kissing occurs in such relationships. However, what threatens the concept of virginity is intercourse.

Interviewee number 10 (a female) stated, "Nowadays, everyone has boyfriends. Well, both sides have certain needs, but women should be more careful since men are not at risk of losing their virginity." The interviewee number 12 (a male) also said that, "As a man, unlike my dad, I do not think that a virgin woman is someone who has never had a relationship with anyone. Such a thing is impossible these days. I personally think that it is not a problem if she has had a boyfriend, but it is important to me that she had no sexual relationship."

The interviewees considered virginity as a femalerelated issue. Unlike their parents, they did not think that having an emotional relationship with the opposite sex should be avoided until marriage. Rather, they defined a range for such a relationship and believed that this type of relationship is acceptable if there is no sexual intimacy.

\section{Virginity as a myth}

The second identified subtheme was virginity as a myth. Three of the female interviewees considered virginity as a concept that is completely related to the female gender. To them, virginity was meaningless and a myth. They perceived it as a fictional story that has become a custom over time and refers to the inequality between women and men, exploitation of women by men, and a bitter myth. Virginity had no meaning or value to this group of interviewees. The interviewee number 14 (a female) said, "A woman is a free human being. Virginity is a lie that men have made up and repeated over time to make women believe it. Why they are not virgins themselves, and what does it mean to be a virgin anyway?"

Interviewee number 30 (a female) stated, "... This is my body. I have to decide for it, not men. Virginity is a myth and a clear indication of inequality between men and women."

\section{Virginity as a commitment}

The next identified subtheme in this study was virginity as a commitment. Five interviewees (three males and two females) believed that virginity means two people' commitment in a relationship. These two individuals might have had relationships with others in the past, but this does not mean the loss of virginity. Virginity means being committed to your emotional partner in a relationship. Therefore, a person's virginity is revealed over time in a relationship. Interviewee number 33 (a male) said, "Having no relationship does not mean being a virgin. Virginity means being just with your partner in a relationship. I don't care about the past life of my girlfriend, even my wife. However, from the day she becomes my wife or girlfriend, it will be important to me if she keeps her virginity. If she does not cheat on me when she is with me. Her past does not matter to me."

Interviewee number 19 (a female) stated, ".... I can give you a lot of examples of those who had a hymen, but cheated on their husbands after marriage. Being a virgin means being committed to your husband."

For some interviewees $(N=5)$, it seemed that the meaning of virginity was different from the meaning of having a hymen. They regarded virginity as being committed and faithful. In fact, having a hymen was not symbol of virginity for them.

\section{Virginity as having an intact hymen}

Virginity as having an intact hymen was another subtheme identified in this study. According to 14 of the interviewees (nine females and five males), virginity meant having an intact hymen. They believed that virginity does not necessarily mean lack of sexual intercourse, but having an intact hymen. Thus, in their views, sexual relations such as anal sex and genital touching were acceptable, and having these types of relations were not considered as violation of virginity.

Interviewee number 20 stated, 'Virginity means having a hymen. When a woman has sex on her wedding night, if no vaginal bleeding occurs, it will be a disgrace for her and it means she had sex prior to her marriage. However, we can have anal sex before we get married, and nobody will find out about it."

Fourteen participants considered the meaning of virginity as having a hymen rather than chastity. It was important for them to have a hymen because of Iran social norms, but it did not mean that they did not have other forms of sexual relationship. In fact, social norms did not lead to abstinence.

\section{Not knowing the meaning of virginity}

The last main theme identified in this study was not knowing the meaning of virginity. Three of the interviewees did not know the meaning of the term 'virginity'.

\section{Discussion}

The findings of the present study varied from the nonacceptance of any relationship to the acceptance of vaginal intercourse. Generally, all of these concepts are categorised into two main themes, including nonacceptance and acceptance of physical intimacy.

The main theme of nonacceptance of physical intimacy was the subtheme of lack of physical contact. It indicated that the relationship with the opposite sex in the form of social networking, chat, phone call, and going 
on dates without physical contact was acceptable for the participants. Only one male mentioned this subtheme. This may mean that this meaning of virginity was less accepted in males than in females. Various studies showed that the likelihood of a romantic date leading to sexual intercourse is considerably high [26].

Also, the main theme of nonacceptance of physical intimacy contained the subtheme of lack of any emotional relationship with the opposite sex. According to this view, the concept of 'virginity' means the absence of any emotional relationship with the opposite sex outside the framework of marriage, and this concept is not specific to the female gender. This view is completely consistent with the policymaking approach used in the field of premarital sexual relations in Iran. However, it should be noted that only two female interviewees had such an opinion. This may indicate that the meaning of virginity as lack of any emotional relationship with the opposite sex was more likely to be accepted by females than by males, although only two out of 18 females mentioned it. Motamedi et al. showed that very few participants agreed with the lack of premarital emotional relationship with the opposite sex [27] before marriage. Therefore, it seems that Iranian health policymakers have not been able to integrate the concept of virginity as a value into the value system of adolescents.

Acceptance of physical intimacy was another main theme which was the most frequently mentioned theme in this study. The most frequent concept that the interviewees referred to was 'virginity as having an intact hymen'. Also, 9 female participants and 5 male participants mentioned this subtheme. This may indicate that the meaning of virginity as having an intact hymen was more likely to be accepted in both genders, especially in females. Females emphasized the importance of having a hymen more, which may be due to the fact that having an intact hymen for a female is highly important in the Iranian society and lack of it has serious consequences. This theme implies that any form of sexual intercourse with the opposite sex in the absence of vaginal intercourse is acceptable and does not harm the concept of virginity. In fact, interviewees linked the concept of virginity as a social concept to having a hymen as a physiological topic. Moreover, 14 participants perceived virginity as having an intact hymen and believed that virginity was only particular to girls and not to boys. Ahmadi referred to the relationship between the concept of virginity and having an intact hymen in the context of Iran and believed that the relationship between these two concepts is one of the reasons for increasing the demand for hymenoplasty [16].

The main theme of 'acceptance of physical intimacy' included other subthemes such as nonpenetrative relationship, virginity as a myth, and virginity as a commitment rather than just not having a relationship. These themes are new interpretations of virginity that provide a different concept for virginity as 'not touched'. The interviewees, who considered virginity as a myth, perceived this phenomenon as a male-dominated view toward the female body which belongs to the distant past. This concept was mentioned by 3 female participants and not mentioned by any male participants, which may indicate that the meaning of virginity as a myth was more likely to be accepted by females. The approach is influenced by the feminist view on the concept of virginity. Milles et al. referred to the role of feminist approach in altering the concept of virginity [28]. Also, 3 male participants and 2 female participants mentioned virginity as a commitment. The interviewees who defined virginity as a commitment or a myth had a different interpretation, far from the current context and condition of Iran. In fact, such interpretation reflects a change in the value system of interviewees and the breakdown of social taboo on the lack of hymen, which is the greatest sign of virginity in the Iranian culture. Motamedi et al. referred to the change of value system of participants regarding premarital sex [28].

Another subtheme derived from the main theme 'acceptance of physical intimacy' was nonpenetrative relationship. This concept was mentioned by 2 male and 2 female participants. According to the participants, any other sexual relations, except for penetrative ones, are accepted and do not harm the concept of virginity. The difference between this subtheme and the subtheme of virginity as having an intact hymen is in accepting anal intercourse. Both of these themes are the results of dominant approach in Iranian society regarding virginity and its relationship with an intact hymen for females. These findings suggest that the probability of getting sexually transmitted disease is high in other types of sexual relations [29].

Although the most reliable policy on STDs prevention is based on the lack of premarital sexual intercourse, the success of this policy is related to the concept of virginity $[22,30]$. Since Iran is an ideological country, and according to Islamic teaching having sex outside marriage is not accepted and is associated with legal and religious punishments, the preferred policy on premarital sexual relations is the policy of banning such relations and respecting purity. Moreover, no education on sexual relation and its risks is provided for the adolescents who are highly prone to such behaviours [31]. On the other hand, virginity is considered as a value in the Iranian culture [14]. Therefore, based on the findings of the present study, 26 of the 36 participants in this study did not consider the various forms of physical intimacy as the violation of virginity and also did not have sufficient information about STDs. This may indicate that 
adolescents with such attitude would probably enter in premarital sexual relations without knowing the dangers. On the other hand, since virginity is only meaningful for females according to the perspective of some interviewees, and studies confirm the existence of such view in the context of Iran [32], the policy of observing chastity, purity, and virginity until marriage cannot grantee the sexual health of male teenagers. Considering the changes in the transmission pattern of AIDS in Iran from injection with a common syringe to sexual intercourse [33], the perspective of interviewees can be a wake-up call for the health policymakers.

Our findings indicated that most interviewees associated the concept of virginity only with females and believed that virginity is meaningless to males. They believed that virginity means having an intact hymen in females [34] and the reason for such a belief is rooted in different concepts of virginity in the context of Iran. Thus, having virginity only for females in Iran has a long history and means chastity, virtue, and modesty for women [16].

\section{Conclusion}

Iran is an ideological country where sexual relations are prohibited outside marriage framework. According to Islamic teachings, having sex outside the marriage framework is not accepted and is associated with legal and religious penalties and punishments, so the selected policies regarding the premarital sexual relations are based on the banning of such relations and respecting purity. Although the most reliable policy on the prevention of STDs is the lack of premarital sex, the success of this policy is closely related to the concept of virginity. The findings of the present study showed that from the perspective of Iranian adolescents, virginity has a wide range of concepts from denying any emotional relationship with the opposite sex to accepting physical intimacy and penetrative relationship. Most interviewees did not consider physical intimacy in any form as the breach of virginity. Thus, the policy of purity and lack of sexual relationship before marriage is inadequate and associated with the risk of STDs, according to the concept of virginity from the perspective of Iranian teenagers. Therefore, Iranian health policymakers must take steps towards modifying the concept of virginity in the value system of adolescents and provide sex education courses to this population group.

\section{Acknowledgments}

Not applicable.

\section{Authors' contributions}

VYF made substantial a contribution to data acquisition and interpretation. MHM made a considerable contribution to study conception and design. SM made a considerable contribution to design of the study, data collection. FZ drafted the manuscript. AAH revised the study critically for important intellectual content. NO made a substantial contribution to study conception and design, data acquisition, analysis, and interpretation. Also, NO agreed to be accountable for all aspects of the work and ensured that questions regarding the accuracy or integrity of any part of the work were appropriately investigated and resolved. All Authors read and approved the final manuscript.

Funding

The authors of this article have not received any funding

\section{Availability of data and materials}

The datasets used in this study are available upon reasonable request.

\section{Ethics approval and consent to participate}

This paper was derived from a PhD thesis and was approved by the Ethics Committee of Kerman University of Medical Sciences, Iran. All participants provided written informed consent. Based on the ethics fundamental regulations in medical science research in Iran, informed consent should be obtained only from the participants if they are 15 years old or over. Thus, in this study, written informed consent was obtained only from the participants.

\section{Consent for publication}

Not applicable.

\section{Competing interests}

The authors declare that they have no competing interests.

\section{Author details}

${ }^{1}$ Health Services Management, Medical Informatics Research Center, Institute for Futures Studies in Health, Kerman University of Medical Sciences, Kerman, Iran. ${ }^{2}$ Health Policy, Health Services Management Research Center, Institute for Futures Studies in Health, Kerman University of Medical Sciences, Kerman, Iran. ${ }^{3}$ Health Policy, Department of Health Management, Policy and Economics, School of Public Health, Bam University of Medical Sciences, Bam, Iran. ${ }^{4}$ Epidemiology, Social Determinants of Health Research Center, Institute for Futures Studies in Health, Kerman University of Medical Sciences, Kerman, Iran. ${ }^{5}$ Epidemiology, Health Modeling Research Center, Institute for Futures Studies in Health, Kerman University of Medical Sciences, Kerman, Iran. ${ }^{6}$ Bam University of Medical Sciences, Sardaran Shahid Square - Shahid Rajaei Boulevard, Bam Postal Code: 7616913555, Iran.

Received: 7 September 2019 Accepted: 7 May 2020

Published online: 19 May 2020

\section{References}

1. Massad SG, Karam R, Brown R, Glick P, Shaheen M, Linnemayr S, et al. Perceptions of sexual risk behavior among Palestinian youth in the West Bank: a qualitative investigation. BMC Public Health. 2014;14(1):1213.

2. Kamarulzaman A. Fighting the HIV epidemic in the Islamic world. Lancet. 2013;381(9883):2058-60

3. DeJong J, Shepard B, Roudi-Fahimi F, Ashford L. Young people's sexual and reproductive health in the Middle East and North Africa. Reprod Heal. 2007; 14(78):8.

4. Nguyen SH, Dang AK, Vu GT, Nguyen CT, Le THT, Truong NT, et al. Lack of Knowledge about sexually transmitted diseases (STDs): implications for STDs prevention and care among dermatology patients in an Urban City in Vietnam. Int J Environ Res Public Health. 2019:16(6):1080.

5. Jain $\mathrm{V}$, Jain $\mathrm{S}$, Jain $\mathrm{C}$. Knowledge, attitude and perception about stds including hiv infection among adolescent girls in indore. J Evol Med Dent Sci 2016;5(72):5307-5310.

6. Olson RM, García-Moreno C. Virginity testing: a systematic review. Reprod Health. 2017:14(1):61

7. McAlister J. True tales of the first time: sexual storytelling in the virginity loss confessional genre. Sexualities. 2017;20(1-2):105-20.

8. Horowitz AD, Bedford E. Graded structure in sexual definitions: categorizations of having "had sex" and virginity loss among homosexual and heterosexual men and women. Arch Sex Behav. 2017;46(6):1653-65.

9. Bhana D. Virginity and virtue: African masculinities and femininities in the making of teenage sexual cultures. Sexualities. 2016;19(4):465-81. 
10. Matswetu VS, Bhana D. Humhandara and hujaya: virginity, culture, and gender inequalities among adolescents in Zimbabwe. SAGE Open. 2018; 8(2):2158244018779107.

11. Khalesi ZB, Simbar M, Azin SA. A qualitative study of sexual health education among Iranian engaged couples. Afr Health Sci. 2017;17(2):382-90.

12. Sharifi N. Female bodies and sexuality in Iran and the search for Defiance: Springer; 2018

13. Manna AAK, Murkshtis MY, Bertovskiy LV, Selezneva NA, Ignatova MA. Adultery and Rape in the Muslim Criminal Law: Comparative Law Analysis. J Adv Res Law Econ. 2017;8(1 (23):113.

14. Robatjazi M, Simbar M, Nahidi F, Gharehdaghi J, Emamhadi M, Vedadhir A, et al. Virginity and virginity testing: then and now. Int J Med Toxicol Forensic Med. 2016;6(1):36-43.

15. Kohan S, Mohammadi F, Mostafavi F, Gholami A. Being single as a social barrier to access reproductive healthcare services by Iranian girls. Int I Heal Policy Manag. 2017;6(3):147.

16. Ahmadi A. Recreating virginity in Iran: Hymenoplasty as a form of resistance. Med Anthropol Q. 2016;30(2):222-37.

17. Ghaffari M, Gharlipour Gharghani Z, Mehrabi Y, Ramezankhani A, Movahed M. Premarital sexual intercourse-related individual factors among Iranian adolescents: a qualitative study. Iran Red Crescent Med J. 2016;18(2):e21220.

18. Patton GC, Sawyer SM, Santelli JS, Ross DA, Afifi R, Allen NB, et al. Our future: a lancet commission on adolescent health and wellbeing. Lancet. 2016;387(10036):2423-78

19. Statistical Center of Iran. Population and Housing Census Results. Tehran: Springer; 2017

20. Kreager DA, Staff J, Gauthier R, Lefkowitz ES, Feinberg ME. The double standard at sexual debut: gender, sexual behavior and adolescent peer acceptance. Sex Roles. 2016;75(7-8):377-92.

21. Oroomiei N. Analysis of policies related to high-risk sexual behaviors, synthetic drugs use and alcohol consumption in adolescents in Iran: Kerman University of Medical Sciences; 2019.

22. Murphy NJ. Virginity pledges as a preventative measures for preventing unwanted sexual, behavioral, and biological outcomes: a systematic review of adolescents and young adults in the US. Ohio: The Ohio State University; 2018. p. 74-9.

23. Bearman PS, Brückner H. Promising the future: virginity pledges and first intercourse1. Am J Sociol. 2015

24. Statistical Centre of Iran. Population and Housing Census [in Farsi]. Tehran; 2017.

25. Silverman D. In: Metzler K, editor. Doing qualitative research: a practical handbook. Washington (DC): SAGE Publications; 2013.

26. Choi EPH, Wong JYH, Lo HHM, Wong W, Chio JHM, Fong DYT. The association between smartphone dating applications and college students' casual sex encounters and condom use. Sex Reprod Healthc [Internet] 2016;9:38-41 Available from: http://www.sciencedirect.com/science/article/ pii/S1877575616300672.

27. Motamedi M, Merghati-Khoei E, Shahbazi M, Rahimi-Naghani S, Salehi M, Karimi $M$, et al. Paradoxical attitudes toward premarital dating and sexual encounters in Tehran, Iran: a cross-sectional study. Reprod Health. 2016;13(1):102

28. Milles K, Holmdahl J, Melander I, Fugl-Meyer K. "Something that stretches during sex": replacing the word hymen with vaginal corona to challenge patriarchal views on virginity. Gend Lang. 2018;12(3):1048-63.

29. Baggaley RF, White RG, Boily M-C. HIV transmission risk through anal intercourse: systematic review, meta-analysis and implications for HIV prevention. Int J Epidemiol. 2010;39(4):1048-63.

30. Ababio P, Yendork JS. "When you talk about virginity It's about females": views on virginity Among University of Ghana students. Sex Cult. 2017;21(2):549-68.

31. Alimoradi Z, Kariman N, Ahmadi F, Simbar M. Preparation for sexual and reproductive self-care in Iranian adolescent girls: a qualitative study. Int Adolesc Med Health. 2017;0(0):94.

32. Khalajabadi Farahani F, Cleland J. Perceived norms of premarital heterosexual relationships and sexuality among female college students in Tehran. Cult Health Sex. 2015;17(6):700-17.

33. Haghdoost AA, Mostafavi E, Mirzazadeh A, Navadeh S, Feizzadeh A, Fahimfar N, et al. Modelling of HIV/AIDS in Iran up to 2014. J AIDS HIV Res. 2011; 3(12):231-9.

34. Kaivanara M. Virginity dilemma: re-creating virginity through hymenoplasty in Iran. Cult Health Sex. 2016;18(1):71-83.

\section{Publisher's Note}

Springer Nature remains neutral with regard to jurisdictional claims in published maps and institutional affiliations.

Ready to submit your research? Choose BMC and benefit from:

- fast, convenient online submission

- thorough peer review by experienced researchers in your field

- rapid publication on acceptance

- support for research data, including large and complex data types

- gold Open Access which fosters wider collaboration and increased citations

- maximum visibility for your research: over $100 \mathrm{M}$ website views per year

At BMC, research is always in progress.

Learn more biomedcentral.com/submissions 